\title{
EVALUATION OF INTRINSIC COLOR STABILITY OF FACIAL SILICONE ELASTOMER REINFORCED WITH DIFFERENT NANOPARTICLES
}

\author{
Nada H. Eltayyar ${ }^{l}$, Ahmad M. Alshimy² and Moustafa N. Abushelib ${ }^{3}$
}

\begin{abstract}
INTRODUCTION: Maxillofacial defects are located in a highly visible body area that is identified with one's identity. An aesthetic and comfortable maxillofacial prosthesis relieves many concerns of the patient and may improve quality of life. Silicone elastomers are more color stable than other materials used in maxillofacial prostheses thus many authors investigated the color stability of those materials under weathering conditions.

OBJECTIVES: This study evaluates the effects of two types of nano-oxides particles at different concentration on the color stability of pigmented silicone MDX4-4210 maxillofacial prosthetic elastomers after artificial aging.

MATERIALS AND METHODS: MDX4-4210 silicone elastomer specimens were fabricated. The control group was incorporated with intrinsic coloring agents, one of nanoparticles group was incorporated with intrinsic coloring agents and titanium oxide nanoparticles $\left(\mathrm{TiO}_{2}\right)$ at different concentration $(2 \%, 2.5$ and $3 \%)$, other nanoparticles group was incorporated with intrinsic coloring agents and aluminum oxide nanoparticles $\left(\mathrm{AL}_{2} \mathrm{O}_{3}\right)$ at different concentration $(2 \%, 2.5 \%$ and $3 \%)$. All specimens were exposed to sunlight, sweat and ultraviolet light for one months. Easy shade spectrophotometer was used to determine the CIELAB $\left(\mathrm{L}^{*} \mathrm{a} \mathrm{b}^{*}\right)$ parameter before and after aging of each specimen, and the values were noted.

RESULTS: The majority of the color changes in all groups were above $3.3 \Delta \mathrm{E}^{*}$ units, which indicates that they were visually observed color change. After one month aging period $\mathrm{TiO}_{2}$ group was more stable than $\mathrm{Al}_{2} \mathrm{O}_{3}$ regarding ultraviolet light. Regarding sweat $\mathrm{TiO}$ group showed more color alteration. $\mathrm{Al}_{2} \mathrm{O}_{3}$ group showed lower color alteration on exposure to sunlight.

CONCLUSIONS: Artificial aging procedures affected the color stability of the maxillofacial silicone with or without nanoparticles incorporation.
\end{abstract}

KEY WORDS: Titanium oxide, intrinsic color, Color stability, artificial aging, Silicon elastomer.

1. B.D.S. Faculty of Dentistry University of Science and Technology

2. Professor of Prosthodontics

3. Assistant Professor of Dental Materials

\section{INTRODUCTION}

Maxillofacial defects are located in a highly visible body area that is identified with one's identity. Therefore, an important maxillofacial prosthetic service is maxillofacial prosthetic fabrication to restore a pleasant facial appearance where the prosthesis is undetectable. An aesthetic and comfortable maxillofacial prosthesis relieves many concerns of the patient and may improve quality of life (1).

Silicone elastomers are more color stable than other materials used in maxillofacial prostheses thus many authors investigated the color stability of those materials under weathering conditions $(2,3)$. Some factors that affect the color stability are ultraviolet (UVA) and (UVB) irradiation from sunlight, temperature, moisture, wind, dust and pollutants (4). However, such factors are artificially simulated by accelerated rates of daylight, moisture, and air (5). Skin, sebaceous oil secretions and skin perspirations have been used in conditioning silicone specimens to identify their effect on color and properties of silicone prostheses (6).

Several studies have found satisfactory results by incorporating nanoparticles (NPs) into polymeric materials (mainly silicone elastomers used for facial prostheses), in terms of protecting such materials from degradation (7). The addition of titanium oxide $(\mathrm{TiO} 2)$ and zinc oxide $(\mathrm{ZnO})$ to polymers can improve the mechanical and optical properties of polymers due to the small size, large specific area, and quantum effect of the NPs, as well as the strong interfacial interaction between the organic polymer and inorganic NPs (8). Although it has been reported that untreated aluminum oxide $\left(\mathrm{Al}_{2} \mathrm{O}_{3}\right)$ powder develops physical properties of high impact acrylic resin (9), there have been no investigations regarding the effect of $\mathrm{Al}_{2} \mathrm{O}_{3}$ powder on the physical properties of silicone elastomers. Therefore, we evaluated the effects of $\mathrm{Al}_{2} \mathrm{O}_{3}$ and $\mathrm{tiO}_{2}$ nano- particles on the color stability of silicone elastomers.

Investigators have used reflectance spectrophotometry to evaluate the color changes of aged materials (10). CIELAB system was widely used for calculation of color change $(\Delta \mathrm{E})$ and is used to evaluate the color stability of silicone elastomer subjected to aging. The $\mathrm{L}^{*} \mathrm{a} * \mathrm{~b} *$ coordinates can be used to calculate color differences or color changes, by using the CIELAB color-difference equation (11).

$\Delta E^{*}=\left[\left(\Delta L^{*}\right) 2+\left(\Delta a^{*}\right) 2+\left(\Delta b^{*}\right) 2\right] 1 / 2$

\section{MATERIALS AND METHODS}

Assessment the effect of varying Nano-oxides particles concentration on the color stability of silicone elastomer has been done in this study by laboratory experiments. Two Nano-oxides were used: $\mathrm{TiO}_{2}$ and $\mathrm{Al}_{2} \mathrm{O}_{3}$ with silicone elastomer MDX4-4210 (Dow Corning Corp., Midland, MI, USA) and the silicone has been pigmented with intrinsic pigments (Factor II Inc., Lakeside, AZ).

\section{Preparation of specimens}

A total of 147 specimens of (MDX4-4210) elastomers were fabricated; control group $(\mathrm{n}=21)$ and two nanoparticles groups $\left(\mathrm{TiO}_{2} \quad(n=63)\right.$ and $\mathrm{Al}_{2} \mathrm{O}_{3} \quad(n=63)$. Nanoparticles groups were subdivided into three subgroups at different nanoparticles concentration $2 \%$ $(n=21), 2.5 \%(n=21)$ and $3 \%(n=21)$. 


\subsection{Preparation of control group specimens}

The control group samples were prepared first by weighing the silicone elastomer by digital scale (Radwag Wagi Elektroniczne - poland), 2\% Bisque FI-SK- Functional Intrinsic Skin color (Factor II Incorporated. USA) by weight of the silicone base was added and two syringes were used to make homogenous mixture and so the incorporated bubbles were eliminated. The appropriate amount of crosslinker were added to silicone color mix in proportion of (10:1), and mixed again by using two syringe, procedure was repeated several time to eliminate further bubbles from erupting and injected into metallic mold. The specimens $(10 \mathrm{~mm}$ diameter $\times 3 \mathrm{~mm}$ thick) were processed in metallic disk-shaped molds after coated with a very small amount of petroleum jelly and wiped with tissue paper very well so the set material could be removed after setting without sticking on the mold. The mold was covered with plastic ruler and clamped with a binder clips. And allowed to polymerize at room temperature for 72 h. After the materials were cured, the specimens were removed from the molds. All specimens were trimmed and were put in sterilization pouch.

\subsection{Preparation of Nano-particles group specimens}

Specimens reinforced with Nano-oxides particles were prepared first by mixing Silicone base with pigment as control group. The two Nano-oxide particles with their three concentrations were weighted with the digital scale and were mixed with silicone crosslinker by mechanical shaker (IKA ®, VORTEX4 BASIC) with $3000 \mathrm{rpm}$ for $20 \mathrm{~min}$ to achieve a homogenous mixture and dispersion of nanoparticles. Nanoparticles crosslinker mix were added to silicone color base mix in proportion of $(10: 1)$ and used two syringe for mixing same as the control group. The mixture were injected into metallic mold, covered and polymerized as control group. All the specimens were saved in sterilization pouch and were classified by numbers and grouped to avoid mixing of specimens.

\section{Color measurement}

All specimens were dried and measured before and after artificial aging. The color measurements were performed with a spectrophotometer (vita easy shade-Germany) (fig.1) According to the CIELAB coordinates color values were obtained. The $\mathrm{L}^{*}$ parameter corresponds to the degree of lightness and darkness (100 ideal white, 0 ideal black), and $a^{*}$ and $b^{*}$ coordinates correspond to red or green chroma $\left(+\mathrm{a}^{*}=\right.$ red, $-\mathrm{a}^{*}=$ green $)$ and yellow or blue chroma $\left(+b^{*}=\right.$ yellow, $-b^{*}=$ blue $)$, respectively.

The color difference $\left(\Delta \mathrm{E}^{*}\right)$ can be calculated by the following equation: $\Delta \mathrm{E}=$

$$
\left[(\Delta L *)^{2}+(\Delta a *)^{2}+\left(\Delta b^{*}\right)^{2}\right]^{1 / 2}
$$

\section{Artificial aging}

The specimens have been attributed to certain environmental factors such as sunlight, ultraviolet light and stored in simulate sweat. The sweat was prepared according to International Organization for Standardization specification, ISO 3160-2 includes $(20 \mathrm{~g} / \mathrm{L} \mathrm{NaCl}, 17.5 \mathrm{~g} / \mathrm{L} \mathrm{NH} 4 \mathrm{OH}, 5 \mathrm{~g} / \mathrm{L}$ acetic acid and $15 \mathrm{~g} / \mathrm{L} \mathrm{d}, 1-$ lactic acid With the $\mathrm{pH}$ adjusted to 4.7 by $\mathrm{NaOH}$ ) (12). The control group and experimental subgroups were divided into three groups for artificial aging: Sunlight group $(n=7)$ : were exposed to sunlight for about 6 hours daily in the period between 10 am and 4 pm, Sweat group $(n=7)$ : were stored in sweat for 12 hours daily,
Ultraviolet group $(n=7)$ : were exposed to ultraviolet light for 12 hours daily using ultraviolet lamp (UV-A) (Blacklight F15wl350 BL-T8, Germany). Each aging group were exposed to artificial aging for 30 days and reading were taken after 10 days, 20 days and 30 days. At the end of the each period, the specimens were removed, cleaned for 15 minutes in distilled water then the color was measured.

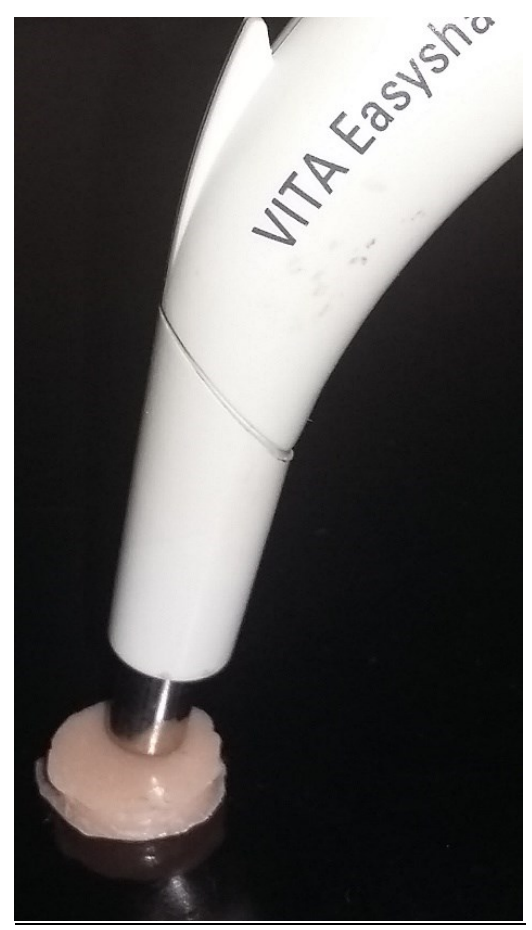

Figure 1: Color reading using VITA Easy Shade.

\section{RESULTS}

The majority of the color changes in all groups were above 3.3 $\mathrm{DE}^{*}$ units, which indicated that they were visually observed color change. Silastic MDX4-4210 mean color alteration $(\Delta \mathrm{E})$ values in control, $\mathrm{TIO}_{2}$ and $\mathrm{AL}_{2} \mathrm{O}_{3}$ subgroups regarding three aging conditions are shown in Table 1 .

Table 1: Mean values (SDs) of $\Delta \mathrm{E}$ for control, TIO2 and AL2O3 groups.

\begin{tabular}{|c|c|c|c|c|}
\hline groups & condition & $\Delta E 10$ days & $\Delta \mathrm{E} 20$ days & $\Delta E \mathbf{E} 30$ days \\
\hline control & sweat & 2.6 & 3.1 & 3.5 \\
\hline control & UV & 5.2 & 4.2 & 3.3 \\
\hline control & sun & 2.4 & 3.5 & 4.4 \\
\hline $\mathrm{Al} 2 \%$ & sweat & 1.6 & 22.5 & 22.7 \\
\hline $\mathrm{Al} 2 \%$ & UV & 6.3 & 6.4 & 7.3 \\
\hline $\mathrm{Al} 2 \%$ & sun & 6.2 & 6.7 & 22.6 \\
\hline $\mathrm{Al} 2.5 \%$ & sweat & 2.7 & 17.1 & 17.3 \\
\hline $\mathrm{Al} 2.5 \%$ & UV & 6.2 & 5.8 & 7.4 \\
\hline $\mathrm{Al} 2.5 \%$ & sun & 2.9 & 4.2 & 20.4 \\
\hline $\mathrm{Al} 3 \%$ & sweat & 10.3 & 18.3 & 26.1 \\
\hline $\mathrm{Al} 3 \%$ & UV & 11.5 & 15 & 16.8 \\
\hline $\mathrm{Al} 3 \%$ & sun & 7.1 & 13.2 & 28.1 \\
\hline Ti $2 \%$ & sweat & 15.6 & 44 & 60 \\
\hline Ti $2 \%$ & UV & 6.8 & 7.4 & 6.6 \\
\hline Ti $2 \%$ & sun & 4.7 & 26.5 & 40 \\
\hline $\operatorname{Ti} 2.5 \%$ & sweat & 4.4 & 58.9 & 59.3 \\
\hline Ti $2.5 \%$ & UV & 4.3 & 19.4 & 19.5 \\
\hline Ti $2.5 \%$ & sun & 6.6 & 11.9 & 51.3 \\
\hline Ti $3 \%$ & sweat & 8.5 & 16.4 & 19.1 \\
\hline Ti $3 \%$ & UV & 2.5 & 17.9 & 18.1 \\
\hline Ti $3 \%$ & sun & 2.7 & 13.8 & 32.9 \\
\hline
\end{tabular}




\section{Effect of nano-particles type}

In comparison between two nanoparticles group $\left(\mathrm{TiO}_{2}\right.$ and $\mathrm{Al}_{2} \mathrm{O}_{3}$ ). Regarding the sunlight after 10 days the $\mathrm{TiO}_{2}$ showed lower color change than $\mathrm{Al}_{2} \mathrm{O}_{3}$. After 20 and 30 days the $\mathrm{Al}_{2} \mathrm{O}_{3}$ showed lower color change than $\mathrm{TiO}_{2}$. Regarding the ultraviolet light after 10 and 30 days the $\mathrm{TiO}_{2}$ showed lower color change than $\mathrm{Al}_{2} \mathrm{O}_{3}$. After 20 days the $\mathrm{Al}_{2} \mathrm{O}_{3}$ showed lower color change than $\mathrm{TiO}_{2}$. Regarding the sweat after 10 and 30 days the $\mathrm{Al}_{2} \mathrm{O}_{3}$ showed lower color change than $\mathrm{TiO}_{2}$. After 20 days the $\mathrm{TiO}_{2}$ showed lower color change than $\mathrm{Al}_{2} \mathrm{O}_{3}$ (fig.2, 3 and 4).

\section{Effect of nano-particles concentration}

In comparison between nanoparticles subgroups $\left(\mathrm{TIO}_{2}\right.$ and $\mathrm{AL}_{2} \mathrm{O}_{3}$ ) regarding the sunlight after 10 days the $\mathrm{TiO}_{2}(3 \%)$ showed lowest color change. After 20 and 30 days the $\mathrm{AL}_{2} \mathrm{O}_{3}(2.5 \%)$ showed lowest color change. Regarding the ultraviolet light after 10 days the $\mathrm{TiO}_{2}(3 \%)$ showed lowest color change. After 20 days the $\mathrm{Al}_{2} \mathrm{O}_{3}$ (2.5\%) showed lowest color change. After 30 days also the $\mathrm{TiO}_{2}(2 \%)$ subgroup showed lowest color change. Regarding the sweat after 10 days the $\mathrm{Al}_{2} \mathrm{O}_{3}(2 \%)$ subgroup showed lower color change. After 20 days the $\mathrm{TiO}_{2}(3 \%)$ were showed lowest color change. After 30 days the $\mathrm{Al}_{2} \mathrm{O}_{3}$ (2.5\%) subgroup showed lowest color change (fig.2, 3 and 4).

\section{Effect of artificial aging}

Among three aging conditions after 30 days the greatest color change was observed in storing in sweat. Ultraviolet light showed the least effect.

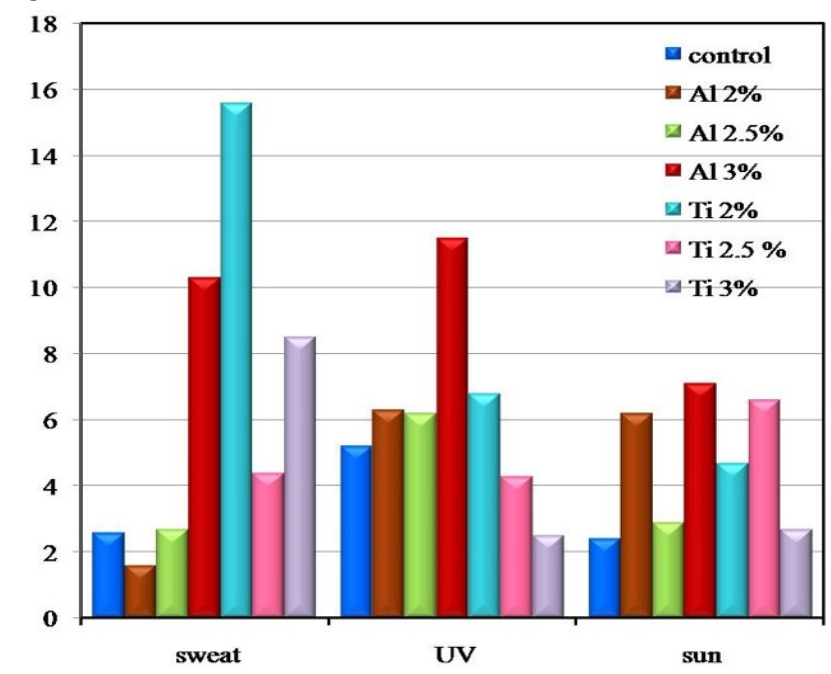

Figure 2: Mean of $\Delta \mathrm{E}$ values of all three groups (control group, $\mathrm{TiO}_{2}$ group, $\mathrm{Al}_{2} \mathrm{O}_{3}$ group) and their interactions with 3 aging conditions (sweat- ultraviolet light -sunlight) after 10 days.

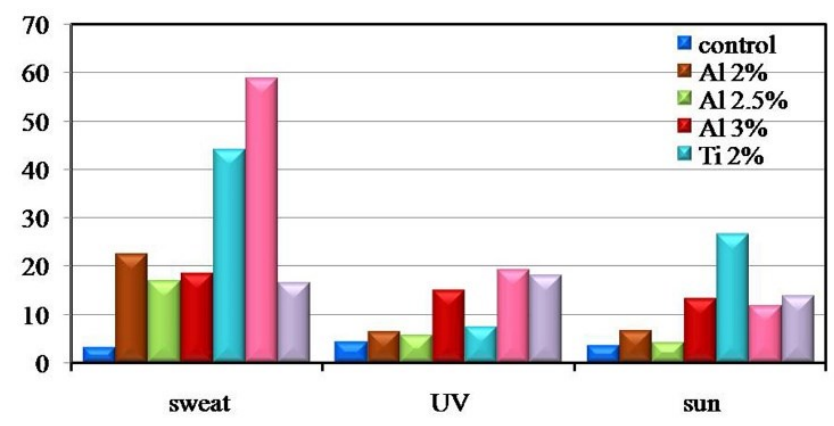

Figure 3: Mean of $\Delta \mathrm{E}$ values of all three groups (control group, $\mathrm{TiO}_{2}$ group, $\mathrm{Al}_{2} \mathrm{O}_{3}$ group) and their interactions with 3 aging conditions (sweat- ultraviolet light -sunlight) after 20 days.

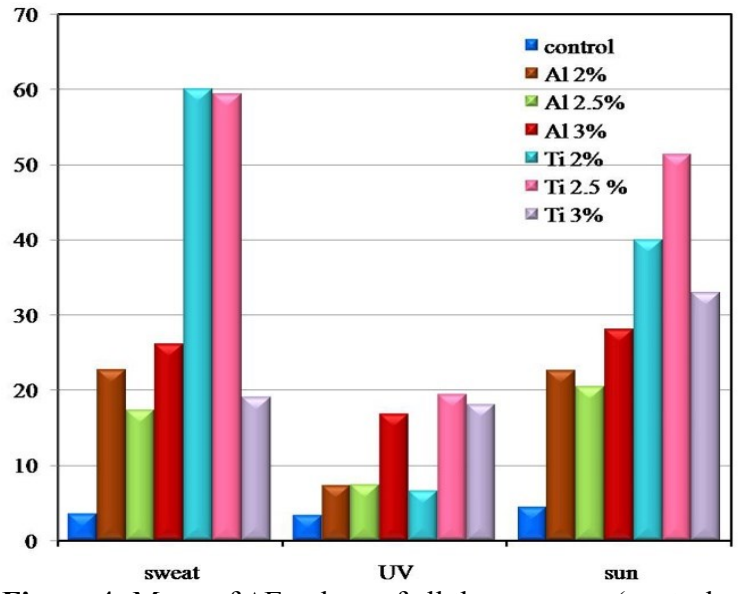

Figure 4: Mean of $\Delta \mathrm{E}$ values of all three groups (control group, $\mathrm{TiO}_{2}$ group, $\mathrm{Al}_{2} \mathrm{O}_{3}$ group) and their interactions with 3 aging conditions (sweat- ultraviolet light -sunlight) after 30 days.

\section{DISCUSSION}

Artificial aging is a useful, effective and fast method to evaluate the color stability of maxillofacial materials. Several research studies have evaluated the color differences of maxillofacial materials after accelerating aging. The weathering of polymers can produce changes in physical and chemical characteristics that cause a significant loss in important mechanical properties that also affect the color of the samples (13).

In the present study accelerated aging were used, which include three aging conditions to test the materials: sunlight exposure, ultraviolet exposure and sweat. Each of these aging conditions affected the materials differently. And different types $\left(\mathrm{TiO}_{2}\right.$ and $\left.\mathrm{Al}_{2} \mathrm{O}_{3}\right)$ and proportions $(2 \%, 2.5$ and $3 \%)$ of NPs were used and according to the results obtained in this study, MDX4-4210 silicone elastomer, whether incorporated by nanoparticles or not, presented color instability $(\Delta \mathrm{E}>0)$, irrespective of the aging period and aging condition. According to the National Bureau of Standards, a color change is considered to be very low when $\Delta \mathrm{E}$ is less than 1 , clinically acceptable when $\Delta \mathrm{E}$ is between 1 and 3 , and clinically noticeable when $\Delta \mathrm{E}$ exceeds 3.39 (14). These differences may be due to inherent unstable nature of silicones which is responsible for color changes in the silicone prostheses according to existing literature (15). Additionally, different NPs may interact differently with various polymer types $(14,16)$. In this study, the lowest mean color change $(\Delta \mathrm{E})$ value after 30 days was (3.3) indicating that all of the evaluated groups had inappropriate degrees of color change.

Researchers have evaluated the effect of different environmental factors and conditioning methods such as simulated perspiration and sebum, disinfectant and cleansing solutions, lipids, microwave energy, on color stability of silicones (17). Polyzois et al (18), Hatamleh and watt (19) observed significant color change after immersion in simulated sebum, acidic and alkaline perspirations. The researches have a deficiency in investigations about the effect of sweat on the color stability of silicone elastomers. For this reason, we investigated the effects of sweat on these material. The results obtained in this study after 30 days showed least color change in control group. In comparison between $\mathrm{TiO} 2$ and $\mathrm{Al}_{2} \mathrm{O}_{3}$ stored in sweat, $\mathrm{TiO}_{2}$ showed higher color changes $(\Delta \mathrm{E})$ at the three interval (10, 20 and 30 days) regardless the concentration 
of $\mathrm{TiO}_{2}$. These might be due to an interaction between the $\mathrm{TiO}_{2}$ nanoparticles and sweat solutions which may be contributed to the chemical composition of the sweat. The smaller the pigment particle, the higher its interaction with the polymeric chain of the silicone (20). Accordingly we believe that the $\mathrm{Al}_{2} \mathrm{O}_{3}$ particles $(20 \mathrm{~nm})$ which are smaller in size than $\mathrm{TiO}_{2}$ (30nm), $\mathrm{Al}_{2} \mathrm{O}_{3}$ NPs are strongly linked with the silicone, and they were not removed easily by the action of the sweat. We Also observed in the study that $\mathrm{TiO}_{2}$ have tendency to agglomerate unlike the $\mathrm{Al}_{2} \mathrm{O}_{3}$ which disperse and uniformly distribute in polymer. These result was in agreement with Waters et al (21), who found that facial prostheses may absorb saliva or sweat from surrounding facial tissue and also after washing the prosthesis in water which may affect the physical properties and also affect the perception of color matching to the surrounding facial tissue.

Although ultraviolet (UV) light is the small fraction of the spectrum of sunlight, it is responsible for most of the damage to colorants and polymers. About $95 \%$ of the UV rays from the sun that reach the earth are UVA rays, with the remaining $5 \%$ being UVB rays (22). Therefore, to mimic the spectrum of ultraviolet (UVA) light, artificial light sources were used in this study, Blacklight lamp were chosen which provide the best available match to ultraviolet (UVA). In the present study among all groups exposed to UV after 30 days control group showed least color change and in comparison between $\mathrm{NP}_{\mathrm{S}}$ groups exposed to ultraviolet light, the $\mathrm{TiO}_{2}$ groups, especially the subgroup with the $(2 \%)$ concentration, exhibited the least degree of color change. As the NPs concentration increased, $\mathrm{TiO}_{2}(2.5 \%$ and $3 \%)$ showed significant color changes $(\Delta \mathrm{E})$. These results were in contrast with Han et al (23) who found that $2.5 \% \mathrm{TiO} 2$ showed the best color stability as a result of evaluation of nano-oxides incorporated into a facial silicone, and in contrast aslo with Andreotti et al (24) who found that incorporation of NPs, especially $2.5 \% \quad \mathrm{TiO}_{2}$, helped in maintaining color stability, microhardness and flexural strength of acrylic resin for artificial sclera after aging. The possible explanations for this could be: First: $\mathrm{TiO}_{2}$ nanoparticles provided more color stability than $\mathrm{Al}_{2} \mathrm{O}_{3}$ due to their ability to provide good UV protection by reflecting or scattering most of the UV rays because of its high refractive index (25) Second: $\mathrm{As} \mathrm{TiO}_{2}$ NPs concentration increased, it showed significant color changes, the chance of agglomeration also increases, resulting in poor dispersion in the elastomer matrix. A higher tendency to agglomerate also decreased UV shielding (26). Takamata and Chalian (27) evaluated the color stability of polydimethyl siloxane (HTV silicone and RTV silicone) by comparing the effects of 6 months of aging at room temperature in a dry and dark room to the effects of aging through exposure to outside conditions, especially sunlight. They concluded that color changes as a result of exposure to sunlight for both HTV and RTV were quite small compared to the effects of 6 months of aging. These results indicate that sunlight and the environment may not be responsible for the color changes which necessitate the replacement of appliances. This study, however, suggested that aging rather than exposure to sunlight results in most of the color changes observed in the HTV and RTV base polymers studied.

In the present study all groups showed color instability on exposure to sunlight which in contrast with Takamata el al (27). The control group showed lower color change than NPS group. These could be related to increasing in silicone crosslinker proportion in $\mathrm{NP}_{\mathrm{S}}$ group elastomer.

\section{CONCLUSION}

Considering the limitations of the present in vitro study, the following conclusions can be drawn.

(1) All groups exhibited great color change regardless artificial aging conditions.

(2) Sweat promoted the greatest color alteration of the facial silicone compared to the other aging conditions.

(3) $\mathrm{TiO}_{2}$ group was more stable than $\mathrm{Al}_{2} \mathrm{O}_{3}$ after 30 days regarding Ultraviolet light.

(4) $\mathrm{Al}_{2} \mathrm{O}_{3}$ group was more stable than $\mathrm{TiO}_{2}$ after 30 days regarding sunlight and sweat.

\section{CONFLICT OF INTEREST}

The authors declare that they have no conflicts of interest.

\section{REFERENCES}

1. Ishigami T, Tanaka Y, Kishimoto Y, Okada M. A facial prosthesis made of porcelain fused to metal: aclinical report. J Prosthet Dent 1997; 77: 564-7.

2. Haug SP, Andres CJ, Moore BK. Color stability and colorant effect on maxillofacial elastomers. Part III: weathering effect on color. J Prosthet Dent 1999; 81: 431-8.

3. Kiat-Amnuay S, Waters PJ, Roberts D, Gettleman L. Adhesive retention of silicone and chlorinated polyethylene for maxillofacial prostheses . J Prosthet Dent 2008; 99: 483-8.

4. Davis A, Sims D. Weathering of polymers. London: Applied Science Publishers, 1983. 1-41.

5. Hulterstrom AK, Ruyter IE. Changes in appearance of silicone elastomers for maxillofacial prostheses as a result of aging. Int J Prosthodont 1999; 12: 498504.

6. Goiato MC, Pesqueira AA, dos Santos DM, Zavanelli AC, Ribeiro Pdo P. Color stability comparison of silicone facial prostheses following disinfection. J Prosthodont 2009; 18: 242-4.

7. Dos Santos DM, Goiato MC, Moreno A, Pesqueira AA, Haddad MF. Influence of pigments and opacifiers on color stability of an artificially aged facial silicone. J Prosthodont 2011; 20: 205-8.

8. Han Y, Zhao Y, Xie C, Powers JM, Kiat-Amnuay S. Color stability of pigmented maxillofacial silicone elastomer: effects of nano-oxides as opacifiers. J Dent 2010; 38(Suppl 2): e100-e5.

9. Ellakwa AE, Morsy MA, EI-sheikh AM. Effect of Aluminum oxide addition on the Flexural strength and thermal diffusivity of heat-polymerized acrylic resin. J Prosthodont 2008; 17: 439-44.

10. Furuse A, Gordon K, Rodrigues FP. Colour-stability and gloss-retention of silorane and dimethacrylate composites with accelerated aging. J Dent 2008; 36: 945-52.

11. Robertson AR. The CIE 1976 color-difference formulae. Color Res Appl 1977; 2: 7-11.

12. Stefaniak ET. Artificial Skin Surface Film Liquids. Patent Application Publication, 2008. Available at: http://www.google.com/patents/US20080311613\#bac kward-citations. 
13. Eleni PN, Katsavou I, Krokida MK, Polyzois GL. Color stability of facial silicone prosthetic elastomers after artificial weathering. Dent Res J 2008; 5: 71-9.

14. Koran A, Yu R, Powers JM, Craig RG. Color stability of a pigmented elastomer for maxillofacial appliances. J Dent Res 1979; 58: 1450-4.

15.Kulkarni RS, Nagda SJ. Colour Stability of Maxillofacial Silicone Elastomers: A Review of the Literature. Eur J Prosthodont Restor Dent 2014; 22: 108-15.

16. Kiat-amnuay S, Beerbower M, Powers JM, Paravina RD. Influence of pigments and opacifiers on color stability of silicone maxillofacial elastomer. J Dent 2009; 37(Suppl1): e45-e50.

17. Dootz ER, Koran A 3rd, Craig RG. Physical properties of three maxillofacial materials as a function of accelerated aging. J Prosthet Dent 1994; 71: 379-83.

18. Polyzois GL, Tarantili PA, Frangou MJ, Andreopoulos AG. Physical properties of a silicone prosthetic elastomer stored in simulated skin secretions. J Prosthet Dent 2000; 83: 572-7.

19. Hatamleh MM, Watts DC. Effect of extraoral aging conditions on Color stability of maxillofacial silicone elastomer. J Prosthodont 2010; 19: 536-43.

20. Mancuso DN, Goiato MC, Santos DM. Color stability after accelerated aging of two silicones, pigmented or not, for use in facial prostheses. Braz Oral Res 2009; 23: 1448.

21. Waters MGJ, Jagger RG, Winter RW. Effect of surface modified fillers on the water absorption of a (RTV) silicone denture soft lining material. J Dent 1996; 24: 297-300.

22. Ultraviolet (UV) Radiation and Cancer Risk. American Cancer Society 2015. are Available at: http://www.cancer.org.

23. Han Y, Zhao Y, Xie C, Powers JM, Kiat-Amnuay S. Color stability of pigmented maxillofacial silicone elastomer: effects of Nano-oxides as opacifiers. J Dent 2010; 38(Suppl 2): e100-e5.

24. Andreotti AM, Goiato MC, Moreno A, Nobrega AS, Pesqueira AA, Dos Santos DM. Influence of nanoparticles on color stability, microhardness, and flexural strength of acrylic resins specific for ocular prosthesis. Int J Nanomedicine 2014; 9: 5779-87.

25. Yang H, Zhu S, Pan N. Studying the mechanisms of titanium dioxide as ultraviolet blocking additive for films and fabrics by an improved scheme. J Appl Polym Sci 2004; 92: 3201-10.

26. Han Y, Kiat-amnuay S, Powers JM. Effect of Nanooxide concentration on the mechanical properties of a maxillofacial silicone elastomer. J Prosthet Dent 2008; 100: 465-73.

27. Takamata T, Moore BK, Chalian VA. An Evaluation of Color Changes of Silicone Maxillofacial Materials after Exposure to Sunlight. Dent Mater J 1989; 8: 26070 . 